\title{
Evaluation of antral motility in humans using manometry and scintigraphy
}

K Jones, M Edelbroek, M Horowitz, W-M Sun, J Dent, J Roelofs, T Muecke, L Akkermans

\begin{abstract}
Recent studies suggest that scintigraphy can be used to evaluate non-invasively antral motility in humans, although scintigraphic techniques have not yet been compared with more conventional measurements of intraluminal pressures by manometry. Simultaneous scintigraphic and manometric measurements of antral motility were performed in nine healthy volunteers. After intubation with a sleeve/sidehole catheter which incorporated five pressure sideholes located at $1.5 \mathrm{~cm}$ intervals spanning the antrum, each subject ingested $100 \mathrm{~g}$ minced beef labelled with $100 \mathrm{MBq}^{99 \mathrm{~m}}$ Tc-chicken liver and 150 ml water. Between 40-43, 60-63, 80-83, and 100-103 minutes after meal ingestion, radioisotopic data were acquired in two second frames. Time-activity curves showing antral 'contractions' resulting from wall motion were derived by drawing small regions of interest over the antrum to coincide with the position of the antral manometric sideholes. Scintigraphic contraction rates approximated $3 /$ minute, whereas antral pressure waves that occluded the lumen were less frequent $(p<0.01$ for all), particularly in the proximal antrum. The amplitude of wall motion, evaluated scintigraphically, and the amplitude of pressure waves were both inversely related to the distance from the pylorus $(\mathbf{r}>-0.32, p<0.05)$ and antral volume $r>-0.29(\mathbf{p}<0.05)$. There were significant relationships between the amplitude of contractions assessed scintigraphically and the number of lumen-occlusive antral pressure waves in the distal antrum $(\mathbf{r}-0.48, p<0.05)$ but not in the more proximal antral regions. It is concluded that scintigraphy can detect antral wall motion with greater sensitivity than manometry, particularly in the proximal antrum. As manometry gives information on the amplitude as well as the temporal and spatial organisation of those contractions which result in lumen occlusion, the combination of scintigraphic and manometric techniques in the evaluation of antral motility shows considerable promise.

(Gut 1995; 37: 643-648)
\end{abstract}

Keywords: antral motility, scintigraphy, manometry.

The mechanical factors responsible for normal and delayed gastric emptying are still poorly understood, largely because of the considerable technical challenges associated with the measurement of the several potentially relevant gastric and small intestinal mechanisms in humans. ${ }^{1}$ Although it is clear that the motor functions of the proximal stomach, antrum, pylorus, and proximal small intestine are closely related, ${ }^{2}$ the emphasis of most studies has been to attempt definition of the role of individual motor components, particularly the contribution of antral contractions, to gastric emptying. Transpyloric flow of digesta is predominately pulsatile, rather than continuous. $^{3-5}$ The characteristics of individual flow pulses, which vary considerably from one cycle to the next, may be more dependent on the temporal and spatial organisation of motor events in different regions of the stomach and proximal small intestine than their amplitude. ${ }^{45}$ The impact of a contraction on luminal flow is influenced by patterns of lumen occlusion. When a contraction indents but does not occlude the lumen, flow can occur, but when the lumen is occluded antegrade and retrograde flow cannot occur. ${ }^{16}$ It follows that an optimum approach to the evaluation of normal and disordered gastric motor function would require concurrent measurements of wall motion generated by muscular contractions, intraluminal pressures, and transpyloric flow on a second by second basis. Consequently, most information is obtained with the simultaneous use of a combination of techniques. ${ }^{1}$

Measurement of intraluminal antral, pyloric, and duodenal pressures is optimally performed by perfusion manometry using a closely spaced sidehole array and a pyloric sleeve sensor. ${ }^{7-10}$ Manometry can readily evaluate the organisation, as well as the amplitude, of lumenocclusive pressure waves. ${ }^{8-10}$ It is, however, a technically complex, invasive technique which is uncomfortable for the subject. Furthermore, it is an insensitive measure of contractions that do not occlude the lumen which occur frequently in the fundus and proximal antrum and may be important in determining both intragastric movement of digesta and transpyloric flow. ${ }^{11} 12$

The use of radionuclide methods has contributed greatly to knowledge about normal and disordered gastric motor function. ${ }^{13-21} \mathrm{We}$ were the first to describe a scintigraphic technique which can recognise intragastric movement of food that occurs as a result of gastric contractions. The frequency and amplitude of individual antral contractions are evaluated by measuring changes in radioactivity within small regions of interest drawn over the antrum. ${ }^{1617}$ Modifications of this technique 

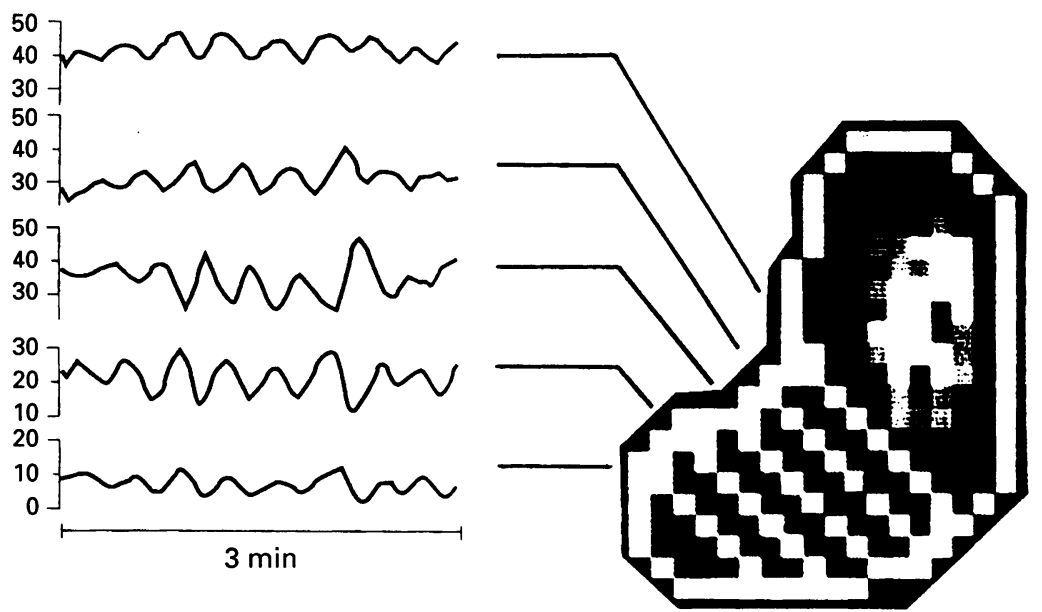

Figure 1: Diagram showing location of antral regions of interest used for the generation of scintigraphic measurements. Time-activity curves representing antral contractile events are shown in five antral adjacent regions in one subject 60-63 minutes after ingestion of the meal. All adjacent regions of interest were drawn perpendicular to the long axis of the antrum with a width of two pixels but are shown in the figure with a width of one pixel for clarity. Antral curves show periodic rhythmic contractions occurring at a frequency of $\approx 3$ cycles per minute.

have been used by others to evaluate normal ${ }^{18}$ and disordered ${ }^{19} 20$ gastric motility as well as the effects of prokinetic drugs. ${ }^{21}$ The noninvasive nature of scintigraphy and its apparent ability to recognise individual contractions represent potential advantages over manometry in the evaluation of antral motility.

The purpose of the present study was to compare scintigraphic and manometric measurements of postprandial antral motility in normal subjects.

\section{Methods}

SUBJECTS

Studies were done in nine healthy volunteers (8 M, 1 F; age 23 (21-25) years, median weight, $67 \mathrm{~kg}$ (range, 62-79); median BMI $22 \mathrm{~kg} \cdot \mathrm{m}^{-2}$ (range, 19-25)) who were all nonsmokers, had no history of gastrointestinal disease or surgery, and were not taking any medication. The study protocol was approved by the Human Ethics Committee of the Royal Adelaide Hospital and written informed consent was obtained from each subject.

\section{INTRALUMINAL MANOMETRY}

The manometric technique used has been described in detail elsewhere. ${ }^{810}$ In brief, the manometric assembly, incorporating a pyloric sleeve sensor with a length of $4.5 \mathrm{~cm}$, had a chain of 10 sideholes spaced at $1.5 \mathrm{~cm}$ intervals. Four of the sideholes were orad to the proximal sleeve end, four were parallel to the sleeve sensor, and two were aborad to the distal sleeve end (Fig 1). The sideholes at each end of the sleeve sensor recorded both intraluminal pressure and antroduodenal transmucosal potential difference (TMPD) simultaneously. ${ }^{810}$ TMPD sideholes were perfused at $0.4 \mathrm{ml} . \mathrm{min}^{-1}$ with degassed normal saline from separate, electrically isolated reservoirs; all other sideholes were perfused with degassed distilled water, also at $0.4 \mathrm{ml} . \mathrm{min}^{-1}$, from a third reservoir. ${ }^{7-10}$ After an overnight fast the manometric assembly was passed transnasally via an anaesthetised nostril and positioned across the pylorus with the correct position of the sleeve determined by measurements of the TMPD gradient at the gastroduodenal junction. ${ }^{810}$ TMPD recordings were continued throughout each experiment in order to maintain the position of the sleeve sensor across the pylorus and five sideholes in the antrum. Antropyloroduodenal pressure waves and TMPD were recorded onto a 12 channel chart recorder (Grass polygraph model 7C, Grass Inc, Quincy, MA, USA), run at a paper speed of $100 \mathrm{~mm} \cdot \mathrm{min}^{-1}$.

In three subjects, the position of the manometric catheter was further evaluated by incorporating markers, each containing $5 \mathrm{MBq}^{57} \mathrm{Co}$ (Amersham Searles, USA), into the manometric assembly at the proximal and distal ends of the sleeve sensor and $4.5 \mathrm{~cm}$ orad and $4.5 \mathrm{~cm}$ aborad to the sleeve end. When the sleeve sensor was positioned correctly (according to TMPD criteria given below) each subject swallowed $150 \mathrm{ml}$ of water, containing a very low dose $(0.3 \mathrm{MBq})$ of ${ }^{99 \mathrm{~m}} \mathrm{Tc}$-sulphur colloid. In all three subjects the antral TMPD sidehole marker was shown to be three pixels $(\approx 2 \mathrm{~cm})$ orad to the pylorus and the sidehole $4.5 \mathrm{~cm}$ orad to the sleeve end was in the ninth pixel $(\approx 6 \mathrm{~cm})$.

\section{RADIONUCLIDE EVALUATION OF GASTRIC EMPTYING AND ANTRAL CONTRACTILE ACTIVITY}

Gastric emptying and antral contractile activity were evaluated for 150 minutes after ingestion of a meal of $100 \mathrm{~g}$ cooked minced beef containing $100 \mathrm{MBq}$ of in vivo labelled ${ }^{99 \mathrm{~m}} \mathrm{Tc}$ sulphur colloid chicken liver (total caloric content $180 \mathrm{kcal} ; 18 \mathrm{~g}$ protein and $10 \mathrm{~g}$ fat) and $150 \mathrm{ml}$ of unlabelled water. ${ }^{14}$ The meal was eaten within five minutes. Throughout the recording period, the subject remained supine with the bed tilted $20^{\circ}$ to the horizontal to avoid possible overprojection of the intestine. An anteriorly positioned gammacamera (Nuclear Chicago, Pho-Gamma $111 \mathrm{HP}$, Digital Equipment Corporation) interfaced to a computer was used to collect data. Apart from periods of rapid acquisition used for evaluation of antral contractions, radionuclide data were acquired in three minute frames. For evaluation of antral contractions, data were acquired every two seconds for the three minute intervals between 40-43, 60-63, $80-83$, and $100-103$ minutes after meal completion. Corrections for subject movement, radionuclide decay, and tissue attenuation were done using previously described methods. ${ }^{14}$

A computer program was used to generate consecutive small regions of interest (ROIs) (two pixels width; $1.34 \mathrm{~cm}$ ) across the antrum perpendicular to its long axis. The first region was three pixels orad to the pylorus, corresponding to the position of the antral TMPD sidehole, the more proximal regions (II through $\mathrm{V}$ ) corresponding to the remaining 


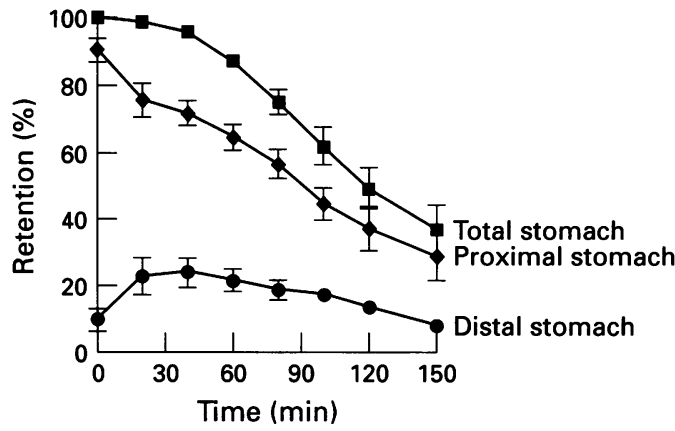

Figure 2: Gastric emptying curves for the solid (minced beef) meal for the total, proximal, and distal stomach. Data are mean (SEM) values.

antral sideholes. Time-activity curves were generated for each ROI and displayed on a computer screen after a smoothing algorithm was applied (Fig 1).

Evaluation of total gastric emptying was based on time-activity curves generated from a ROI drawn around the stomach. ${ }^{13} 14$ This analysis included counts from fast acquisition frames. The amount of isotope in the proximal and distal stomach was evaluated by drawing proximal and distal ROIs, in which the proximal region corresponds to the fundus and proximal corpus and the distal region to the distal corpus and antrum. ${ }^{13}$

\section{DATA ANALYSIS}

Manometric and scintigraphic data from the remainder of the recording period obtained between 40-43, 60-63, 80-83, and 100-103 minutes after ingestion of the meal were evaluated separately.

\section{Manometry}

Pressure waves were analysed only when the sleeve sensor was positioned correctly across the pylorus, according to previously defined TMPD criteria, and their amplitude was $\geqslant 10$ $\mathrm{mm} \mathrm{Hg} .{ }^{810}$ Using these criteria only 'lumenocclusive' pressure waves are evaluated. ${ }^{79}$ The TMPD criteria were that the duodenal TMPD should be equal to or more positive than -15 $\mathrm{mV}$, the antral TMPD should be equal to or more negative than $-20 \mathrm{mV}$, and the difference between the two readings should be at least $15 \mathrm{mV} .810$

The number and amplitude of phasic antral pressure waves in the proximal five antral sideholes (including the antral TMPD sidehole) were evaluated. Isolated pyloric pressure waves (IPPWs), classified as pressure waves $\geqslant 10 \mathrm{~mm}$ $\mathrm{Hg}$ recorded by the sleeve sensor in the absence of any discernible deflection in the antral or duodenal TMPD channels, provided that this pressure wave was recorded by no more than one of the other two sideholes along the sleeve length ${ }^{810}$, were excluded from analysis.

\section{Scintigraphy}

The number of antral contractions (and antral contraction rate) were calculated in the five antral ROIs by a semiautomated program using the time interval between successive peaks and troughs. Peaks and troughs were both expressed as a percentage of counts/second/pixel in the total stomach. Based on the values for peak $(P)$ and trough (T) counts the amplitude of antral wall movement was evaluated by deriving an 'occlusion percentage' as $(1-T / P) \times 100$. The number of contractions with an occlusion percentage $\geqslant 10 \%$ was counted. The amount of the solid meal (volume) in each antral ROI was calculated as $w \pi(d / 2),{ }^{2}$ in which ' $d$ ' represented the number of pixels across each region and ' $w$ ' the width of the region $(1.34 \mathrm{~cm})$.

Emptying curves (expressed as the percentage retention of isotope $v$ time) were derived for total, proximal, and distal stomach ROIs. For the total stomach, the lag phase before any isotope emptied from the stomach; the amount of the solid meal remaining in the stomach at $40,60,80$, and 100 minutes; and the $50 \%$ emptying time were calculated. The lag phase was determined visually by the frame preceding that in which activity appeared in the proximal small intestine. ${ }^{1}$ The proximal stomach $50 \%$ emptying time and the maximum content of the distal stomach were calculated in addition to the retention of isotope in the proximal and distal stomach at 40,60, 80, and 100 minutes. ${ }^{13} 14$

\section{STATISTICAL ANALYSIS}

Manometric and scintigraphic data (expressed as median values and interquartile range) were evaluated independently for the effect of postprandial time, position relative to the pylorus, and antral volume by analysis of covariance. The relationships between pressure waves and wall movements in each ROI were evaluated by ANOVA and Fisher's LSD test. A p value $<0.05$ was considered significant in all analyses.

\section{Results}

All subjects tolerated the study well and there were no adverse effects. The sleeve sensor was correctly positioned across the pylorus throughout all three minute, fast frame acquisitions.

\section{SCINTIGRAPHY}

\section{Gastric emptying}

The overall emptying pattern of the minced beef approximated a linear function after an initial lag phase. The mean (SEM) lag phase was $21.9(3.4)$ minutes, the total stomach $50 \%$ emptying time was $122(9.8)$ minutes, the proximal stomach $50 \%$ emptying time $98(8 \cdot 2)$ minutes, and the maximal content of the distal stomach $23 \cdot 8(4 \cdot 3) \%$ (Fig 2).

\section{Evaluation of antral motility}

When the content of the antrum was maximum the count rate was $25 \cdot 2(3 \cdot 6)$ counts/s/pixel in each ROI (Fig 2). 


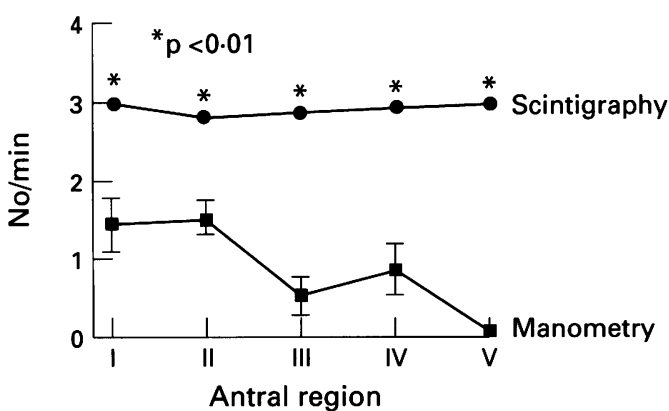

Figure 3: Frequency of scintigraphic and manometric events at five antral sites at 60 minutes postprandially. There are more scintigraphic than manometric events at all antral sites $(p<0 \cdot 01)$. Data are mean (SEM) values.

Contraction rate. Figure 3 shows timeactivity curves in the five antral regions (two pixel width), from the distal (region I) to the proximal antrum (region $\mathrm{V}$ ) in one subject at 60-63 minutes after ingestion of the meal. There are about nine cycles of varying amplitude in the three minute frame. Peaks are presumed to relate to the onset of a contraction and troughs to maximum contraction. There was no change in contraction rate over time. There were fewer contractions in the more proximal region(s) (IV, V) compared with more distal regions (I, II, III) $(\mathrm{p}<0.05)$ (Table I).

Occlusion \%. The amplitude of antral wall movement assessed scintigraphically was inversely related to the postprandial time $(p<0.001)$. The occlusion percentage also decreased $(p<0.001)$ with increasing distance from the pylorus. Moving from the most distal antral region (I) to the most proximal region (V), the percentages of wall movements with $\geqslant 10 \%$ occlusion were $94 \cdot 9 \%, 87 \cdot 7 \%, 82 \cdot 8 \%$, $75.7 \%$, and $69 \cdot 6 \%$ respectively (Table I). There were significant inverse relationships between occlusion percentages and both orad distance from the pylorus $(r=-0.47$, $\mathrm{p}<0.001)$ and regional volume $(\mathrm{r}=0.29$, $\mathrm{p}<0 \cdot 005)$.

\section{MANOMETRY}

Rate of pressure waves

There was no change in the frequency of pressure waves over time (Table II). There were fewer antral waves $(p<0.01)$, and pressure waves were virtually absent in the more proximal region(s) (III, IV, V). There was an inverse relationship $(\mathrm{r}=-0.51$, $p<0.001$ ) between the number of antral waves and the orad distance from the pylorus.

\section{Amplitude}

The amplitude of pressure waves did not change with time. The amplitude of pressure waves decreased from the distal to the proximal antrum $(p<0.01)$. Moving from the most distal region (I) to the most proximal region $(\mathrm{V})$, the percentages of pressure waves $\geqslant 10$ $\mathrm{mm} \mathrm{Hg}$ were $76 \%, 61 \%, 44 \%, 35 \%$, and $41 \%$ respectively (Table II). There was an inverse relationship between the amplitude and both orad distance from the pylorus $(r=-0.32$; $\mathrm{p}<0.05)$ and regional volume $(\mathrm{r}=-0.49$; $\mathrm{p}<0.0001$ ).

\section{RELATIONSHIP BETWEEN SCINTIGRAPHIC AND MANOMETRIC MEASUREMENTS}

The frequency of lumen-occlusive antral pressure waves was less than the number of scintigraphic contractions in all regions $(p<0.01)$ (Fig 3). There were significant relationships between the extent of antral wall motion evaluated scintigraphically (occlusion $\%)$ and the number of antral pressure waves in region $I(r=0.48, p<0.05)$, but not in more distal regions. There was no significant relationship between the occlusion percentage and the median amplitude of pressure waves. There were also no significant relationships between either scintigraphic or manometric measurements of antral motility and overall rates of gastric emptying.

\section{Discussion}

This is the first study which has evaluated the precision of intraluminal perfusion manometry and scintigraphy in the evaluation of antral motility in humans. Our results confirm the previous suggestion ${ }^{16-21}$ that scintigraphy can provide a sensitive measure of movement of intragastric content resulting from antral contractions in both the distal and the proximal antrum. In contrast, the frequency of lumenocclusive antral pressure waves decreased considerably with increasing distance from the pylorus, and these were virtually absent in the

TABLE I Frequency of antral contractions assessed scintigraphically (no/min) in the five regions of interest (ROI) (from distal to proximal antrum) between 40-43, 60-63, 80-83, and 100-103 minutes after meal ingestion. The total number of contractions and the number with an occlusion percentage $\geqslant 10 \%$ are shown. (Values median, interquartile range)

\begin{tabular}{|c|c|c|c|c|c|}
\hline \multirow[b]{2}{*}{$R O I$} & \multirow[b]{2}{*}{ Threshold } & \multicolumn{4}{|l|}{ No of contractions } \\
\hline & & $40-43 \min$ & $60-63 \min$ & $80-83 \min$ & $100-103 \mathrm{~min}$ \\
\hline $\begin{array}{l}\text { II } \\
\text { III } \\
\text { IV } \\
\text { V }\end{array}$ & $\begin{array}{l}\text { None } \\
\geqslant 10 \% \text { occlusion } \\
\text { None } \\
\geqslant 10 \% \text { occlusion } \\
\text { None } \\
\geqslant 10 \% \text { occlusion } \\
\text { None } \\
10 \% \text { occlusion } \\
\text { None } \\
10 \% \text { occlusion }\end{array}$ & $\begin{array}{l}2 \cdot 83(2 \cdot 71-3 \cdot 00) \\
2 \cdot 75(2 \cdot 67-2 \cdot 92) \\
2 \cdot 83(2 \cdot 83-3 \cdot 00) \\
2 \cdot 50(2 \cdot 33-2 \cdot 67)^{\star} \dagger \\
2 \cdot 67(2 \cdot 67-2 \cdot 96) \\
2 \cdot 67(2 \cdot 00-2 \cdot 67)^{\star} \dagger \\
2 \cdot 83(2 \cdot 77-3 \cdot 12) \\
2 \cdot 17(1 \cdot 50-2 \cdot 67)^{\star} \dagger \\
2 \cdot 83(2 \cdot 83-3 \cdot 00) \\
1 \cdot 67(0 \cdot 83-2 \cdot 00)^{\star} \dagger\end{array}$ & $\begin{array}{l}3.00(2 \cdot 96-3.00) \\
2 \cdot 67(2 \cdot 58-3.08) \\
2 \cdot 83(2 \cdot 67-2 \cdot 88) \\
2 \cdot 67(2 \cdot 50-2 \cdot 67)^{\star} \\
2 \cdot 83(2 \cdot 79-3 \cdot 00) \\
2 \cdot 67(2 \cdot 25-2 \cdot 67)^{\star} \dagger \\
3.00(2 \cdot 79-3.00) \\
2 \cdot 67(1 \cdot 33-2 \cdot 75)^{\star} \\
3.00(3 \cdot 00-3.00) \\
1.67(0.67-2 \cdot 42)^{\star} \dagger\end{array}$ & 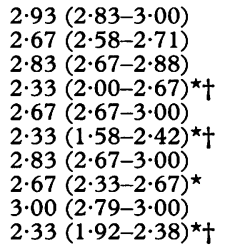 & 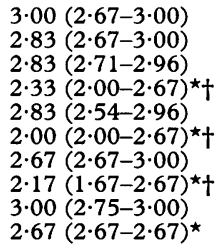 \\
\hline
\end{tabular}

${ }^{\star} \mathrm{p}<0.05$ contractions $\geqslant 10 \%$ occlusion versus all contractions. $\mathrm{tp}<0.05$ proximal regions versus most distal region (I). 
TABLE II Frequency of antral motor events (no/min) assessed scintigraphically (contractions) and manometrically (lumen-occlusive pressure waves) for the five regions of interest (ROI) (from distal to proximal antrum) between 40-43, $60-63,80-83$, and 100-103 minutes after meal ingestion. The total number of pressure waves with an amplitude $\geqslant 10$ $\mathrm{mm} \mathrm{Hg}$ and contractions with an occlusion percentage $\geqslant 10 \%$ are shown. (Values median, interquartile range)

\begin{tabular}{|c|c|c|c|c|c|}
\hline \multirow[b]{2}{*}{$R O I$} & \multirow[b]{2}{*}{ Threshold } & \multicolumn{4}{|c|}{ No of pressure waves and contractions } \\
\hline & & $40-43 \mathrm{~min}$ & $60-63 \mathrm{~min}$ & $80-83 \mathrm{~min}$ & $100-103 \mathrm{~min}$ \\
\hline I & $\begin{array}{l}\geqslant 10 \% \text { occlusion } \\
\geqslant 10 \mathrm{~mm} \mathrm{Hg}\end{array}$ & $\begin{array}{l}2.75(2.67-2.92) \\
1.67(1.33-1.83)\end{array}$ & $\begin{array}{l}2.67(2.58-3.08) \\
1.67(0.67-2.08)\end{array}$ & $\begin{array}{l}2.67(2.58-2.71) \\
0.67(0.33-1.42) \dagger\end{array}$ & $\begin{array}{l}2.83(2.67-3.00) \\
0.50(0.00-1.00) \dagger\end{array}$ \\
\hline \multirow[t]{2}{*}{ II } & $\geqslant 10 \%$ occlusion & $2.50(2.33-2.67)^{\star}$ & $2.67(2.50-2 \cdot 67)$ & $2.33(2.00-2.67)^{\star}$ & $2 \cdot 33(2 \cdot 00-2 \cdot 67)^{\star}$ \\
\hline & $\geqslant 10 \mathrm{~mm} \mathrm{Hg}$ & $1.33(0.50-1.50)^{\star}$ & $0.67(0.58-1.17)^{\star}$ & $0.33(0.25-1.33)^{\star} \dagger$ & $0.17(0.00-0.67)^{\star} \dagger$ \\
\hline \multirow[t]{2}{*}{ III } & $\geqslant 10 \%$ occlusion & $2.67(2.00-2 \cdot 67)^{\star}$ & $2 \cdot 67(2 \cdot 25-2 \cdot 67)^{\star}$ & $2.33(1.58-2.42)^{\star}$ & $2 \cdot 00(2 \cdot 00-2 \cdot 67)^{\star}$ \\
\hline & $\geqslant 10 \% \mathrm{~mm} \mathrm{Hg}$ & $0.00(0.00-0.00)^{\star}$ & $0.00(0.00-0.42)^{\star}$ & $0.00(0.00-1.00)^{\star}$ & $0.17(0.00-0.67)^{\star}$ \\
\hline \multirow[t]{2}{*}{ IV } & $\geqslant 10 \%$ occlusion & $2 \cdot 17(1.50-2.67)^{\star}$ & $2.67(1.33-2.75)$ & $2.67(2.33-2.67)^{\star}$ & $2.17(1.67-2.67)^{\star}$ \\
\hline & $\geqslant 10 \% \mathrm{~mm} \mathrm{Hg}$ & $0.00(0.00-0.00)^{\star}$ & $0.00(0.00-0.33)^{\star}$ & $0.00(0.00-0 \cdot 17)^{\star}$ & $0.00(0.00-0.33)^{\star}$ \\
\hline \multirow[t]{2}{*}{ V } & $\geqslant 10 \%$ occlusion & $0.67(0.83-2.00)^{\star}$ & $1.67(0.67-2.42)^{\star}$ & $2.33(1.92-2.38)^{\star}$ & $2 \cdot 67(2.67-2.67)^{\star}$ \\
\hline & $\geqslant 10 \% \mathrm{~mm} \mathrm{Hg}$ & $0.00(0.00-0.00)^{\star}$ & $0.00(0.00-0.00)^{\star}$ & $0.00(0.00-0.00)^{\star}$ & $0.00(0.00-0.00)^{\star}$ \\
\hline
\end{tabular}

${ }^{\star} p<0.05$ proximal regions versus most distal region (I). $\mathrm{tp}<0.05$ earlier postprandial time periods versus $40-43$ minutes.

proximal antrum. Only in the distal antrum was there a relatively close correlation between motor events evaluated by scintigraphy and manometry.

It is now recognised that disordered gastric motility, particularly that which results in delayed emptying, occurs frequently and may contribute to upper gastrointestinal symptoms, impaired oral drug absorption, and, in patients with diabetes mellitus, poor blood glucose control. ${ }^{1}$ Although the results of animal studies indicate that no single motor region should be considered to exert the dominant control over gastric emptying 24522 and that the rate of emptying is dependent on the relationship between motor events in the proximal stomach, antrum, pylorus, and proximal small intestine, ${ }^{22}$ many studies have attempted to ascribe delay in gastric emptying to dysfunction of one region of the stomach, usually the antrum. While the antrum is involved in the grinding of solid food into small particles ${ }^{23}$ and both fasting and postprandial antral hypomotility have been shown in patients with gastroparesis, ${ }^{124-26}$ the role of the antrum in the control of the transpyloric flow of digesta remains uncertain. ${ }^{5}$ Furthermore, antral motility has characteristically been evaluated as an 'index' ${ }^{24}$ which takes into account both the frequency and amplitude of pressure waves

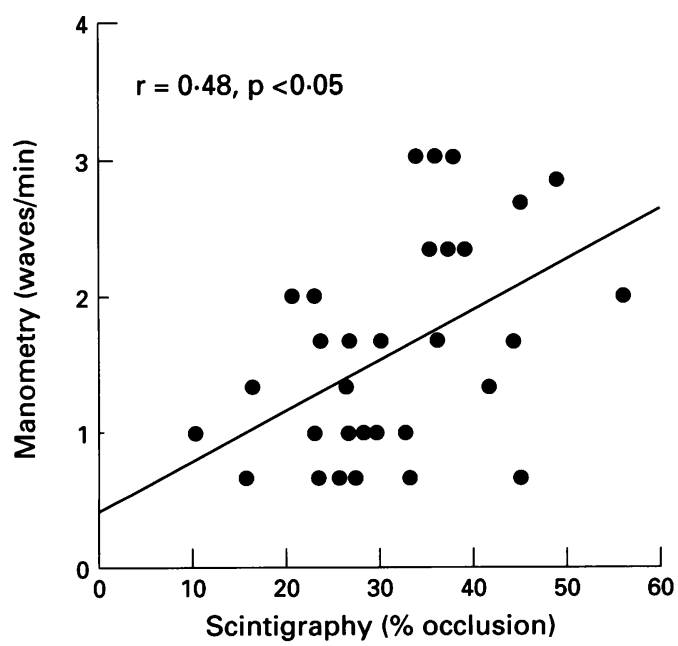

Figure 4: Relationship between the extent of wall motion (scintigraphy) and pressure waves (manometry) in the distal antrum (4-5.5 cm aborad to the pylorus). The number of lumen-occlusive pressure waves is significantly related to the amplitude of wall motion in this region $(r=0.48 ; p<0.05)$. or contractions, but provides no information about the organisation of these motor events. The latter is likely to be an important determinant of their mechanical consequences. ${ }^{45}$ Recent studies, including our own, indicate that the motor dysfunctions in gastroparesis are heterogenous and that abnormal organisation of postprandial gastropyloroduodenal motility is an important factor. ${ }^{27}$ In contrast to the relatively stereotyped gastric pacemaker discharge, which determines the frequency of antral contractions, patterns of lumen occlusion generated by antral contractions are extremely complex, variable, and rarely conform to a peristaltic pattern. ${ }^{9}$ It is not therefore surprising that whether a contraction results in occlusion of the lumen or not is critically important in determining its impact on luminal flow. For example, localised pyloric contractions probably play a major role in the regulation of gastric emptying by acting as a brake. ${ }^{6}$ Patterns of transpyloric flow (pulse volume and frequency) also vary widely from one contraction cycle to the next depending on intragastric volume and feedback from small intestinal luminal receptors. ${ }^{35} 1022$

Our observations confirm that intraluminal manometry is an insensitive technique for the evaluation of contractile activity in the proximal antrum. ${ }^{711}$ In contrast, scintigraphy was able to detect regular contractions at the pacemaker frequency throughout the distal stomach after a solid meal, but could not identify those contractions which resulted in lumen occlusion. Scintigraphy is therefore probably the most sensitive non-invasive technique for measurement of antral contractions. With the previously established roles of scintigraphy in measuring both total stomach emptying ${ }^{1}$ and the intragastric distribution of digesta, ${ }^{13}$ this finding strengthens its use as both a clinical and research technique. Real time ultrasound techniques can also be used to measure both wall motion and gastric emptying. ${ }^{28}$ However, while ultrasound and scintigraphic measurements of wall motion have not been compared formally, the utility of scintigraphy is likely to be much greater. Our observations therefore indicate that the combination of scintigraphic evaluation of antral contractile activity with manometric measurements of gastropyloroduodenal pressures will provide complimentary information about both normal and disordered gastric motility. 
This work was supported by grants from the National Health and Medical Research Council of Australia and from the Netherlands Organization for Research, Council for Medical Research (NWO-GBMW; grant \#900-522-082).

This paper was accepted as an oral presentation in the technologist section of the $41 \mathrm{st}$ Annual Meeting of the Society of Nuclear Medicine, 5-8 June 1994, Orlando, Florida. It was published in abstract form: Jones KL, Edelbroek MAL, Muecke T, Horowitz M, Sun W-M, Dent J, Akkermans LMA, Chatterton BE. Scintigraphic and manometric evaluation of antral motility in humans. $\mathcal{F}$ Nuc Med Technol 1994; 22 (2): 108.

1 Horowitz M, Dent J. Disordered gastric emptying: mechanical basis, assessment and treatment. Baillieres Clin Gastroenterol 1991; 5: 371-407.

2 Heddle R, Miedema BW, Kelly KA. Integration of canine proximal gastric, antral, pyloric and proximal duodenal motility during fasting and after a liquid meal. Dig Dis $\mathrm{Sci}$ 1993; 38: 856-9.

3 Malbert CH, Ruckebusch Y. Relationship between pressure and flow across the gastroduodenal junction in the dog Am f Physiol 1991; 264: G653-7.

4 Malbert CH, Serthelon IP, Dent J. Changes in antroduodenal resistance induced by cisapride in conscious dogs. Am f Physiol 1992; 263: 6202-8.

5 Malbert CG, Mathis C. Antropyloric modulation of the transpyloric flow of liquids in pigs. Gastroenterology 1994; 107: $37-46$

6 Tougas G, Anvari M, Dent J, Somers S, Richards D, Stevenson G. Relation of pyloric motility to pyloric opening and closure in healthy subjects. Gut 1992; 33: 466-71.

ing and closure in healthy subjects. Gut 1992; 33: 466-71. Schee EJ. Evaluation of patterns of human antral and pyloric motility with an antral wall motion detector. $\mathrm{Am} \mathcal{F}$ Physiol 1990; 258: G616-23.

8 Heddle R, Dent J, Toouli J, Read NW. Topography and measurement of pyloric pressure waves and tone in humans. Am F Physiol 1988; 255: G490-7.

9 Sun W-M, Malbert $\mathrm{CH}$, Jones $\mathrm{K}$, Horowitz M, Dent J. Variation in spatial patterns of antropyloric pressure waves - a determinant of gastric mechanics? Gastroenterology 1993; 104: A589.

10 Edelbroek $M$, Horowitz M, Dent J, Sun W-M, Malbert C, Smout A, Akkermans L. Effects of duodenal distension on fasting and postprandial antropyloroduodenal motility in fasting and postprandial antropyloroduodena

11 Valori RM, Collins SM, Daniel EE, Reddy SN, Shannon S, Jury J. Comparison of methodologies for the measurements of antroduodenal motor activity in the dog. Gastroenterology 1986; 91: 546-53.

12 Malbert $\mathrm{CH}$, Dent J, Jamieson GG. Manometric correlates of gastric wall motion. Gastroenterology 1992; 102: A418.

13 Collins PJ, Horowitz M, Chatterton BG. Proximal, distal and total stomach emptying of a digestible solid meal in normal subjects. Br f Radiol 1988; 61: 12-8.

14 Collins PJ, Horowitz M, Cook DJ, Harding PE, Shearman DJC. Gastric emptying in normal subjects. A reproducible technique using a single scintillation camera and computer system. Gut 1983; 24: 1117-25.

15 Camilleri $M$, Mecker Zinsmeister AR. Relation between antral motility and gastric emptying of solids and liquids in humans. $A m \mathcal{F}$ Physiol 1985; 249: G580-5.

16 Akkermans LMA, Jacobs F, Hong-Yoe O, Roelofs JMM Wittebol P. A noninvasive method to quantify antral contractile activity in man and dog (a preliminary report). In: Christensen J, ed. Gastrointestinal motility. New York: Raven Press, 1980: 195-202.

17 Jacobs F, Akkermans LMA, Hong-Yoe O, Hoekstra A, Wittebol P. A radioisotope method to quantify the function of fundus, antrum and their contractile activity in gastric emptying of a semi-solid meal. In: Wiebeck M, ed. Motility of the digestive tract. New York: Raven Press, 1982: 233-40.

18 Urbain J-LC, Cutsem EV, Siegel JA, Mayeur S, Vandecruys A, Janssens, et al. Visualization and characterization of A, Janssens, et al. Visualization and characterization of gastric contractions using a radi

19 Urbain J-LC, Vekemans MC, Bouillon R, Van Cauteren J, Bex M, Mayeur SM, et al. Characterization of gastric antral motility disturbances in diabetes using a scintigraphic technique. $\mathcal{f}$ Nucl Med 1993; 34: 576-81.

20 Stacher G, Bergmann H, Wiesnagrotzski S, Kiss A, Schneider C, Mittelbach G, et al. Intravenous cisapride accelerates delayed gastric emptying and increases antral contraction amplitude in patients with primary anorexia nervosa. Gastroenterology 1987; 92: 1000-6.

21 Stacher G, Peeters TL, Bergmann $H$, Wiesnagrotzki $S$, Schneider C, Granser-Vacariu GV, et al. Erythromycin effects on gastric emptying, antral motility and plasma effects on gastric emptying, antral motility and plasma motilin and pancreatic polypeptide co

22 Horowitz $M$, Dent J. The study of gastric mechanics and flow - a Mad Hatter's tea party starting to make sense. Gastroenterology 1994; 107: 302-6.

23 Meyer JH, Thompson JB, Cohen MB, Schadchehr A, Mandiola SA. Sieving of solid foods by the canine stomach and sieving after surgery. Gastroenterology 1979; 76: 804-13.

24 Camilleri M, Malagelada J-R. Abnormal intestinal motility in diabetics with the gastroparesis syndrome. Eur $\mathrm{F}$ Clin Invest 1984; 14: 420-7.

25 Bortolotti M, Sarti P, Barbera L Brunelli F Gastric myoelectric activity in patients with chronic ideopathic myoelectric activity in patients with chronic ideopathic gastropare $104-8$.

26 Kerlin P. Postprandial antral hypomotility in patients ideopathic nausea and vomiting. Gut 1989; 30: 54-9.

27 Fraser R, Horowitz M, Maddox A, Dent J. Organisation of antral, pyloric and duodenal motility in patients with gastroparesis. Fournal of Gastroenterological Motility 1993; 5: $167-75$.

28 Hausken $T$, Odengaard S, Matre $K$, Berstad A. Antroduodenal motility and movements of luminal contents studied by duplex sonography. Gastroenterology 1992; 102: 1583-90. 